\title{
Myocardial bridging in the course of coronary arteries and its clinical significance
}

\author{
Gunjan Rai', Soumya Khanna', Royana Singh ${ }^{2}$ \\ ${ }^{1}$ Assistant Professor, Department of Anatomy, Institute of Medical Sciences, Banaras Hindu University, Varanasi, \\ Uttar Pradesh, India, ${ }^{2}$ Professor, Department of Anatomy, Institute of Medical Sciences, Banaras Hindu University, \\ Varanasi, Uttar Pradesh, India
}

Background: Sudden death in young adults in absence of any risk factor related to coronary arterial disease has been reported. It could be because of some unrecognized congenital coronary artery anomalies like myocardial bridging. The clinician should keep myocardial bridging as a differential diagnosis in cases of sudden death in young individuals having no risk factors of coronary artery diseases. Aims and Objective: The present study was conducted to know the prevalence of myocardial bridge and percentage of distribution of myocardial bridges in the course of different coronary arteries of cadaveric hearts. Material and Methods: The study was conducted in the department of Anatomy, IMS, BHU Varanasi. Total numbers of 49 formalin preserved hearts were taken for the study. The hearts were meticulously dissected to see the distribution and location of myocardial bridge. Coronary arteries with myocardial bridge were photographed and data was statistically analyzed. Results: Out of 49 hearts, 26(53.06\%) showed myocardial bridging. Total numbers of bridges were found to be 34 in number. Among the 26 myocardial bridged hearts 8 hearts $(30.76 \%)$ showed double myocardial bridges and 18 hearts (69.23\%) showed single myocardial bridges. In hearts with double myocardial bridging, 5 of them showed myocardial bridging in the territory of both anterior interventricular artery (AIVA) and posterior interventricular artery (PIVA) and 3 showed bridging in the territory of anterior interventricular artery and its diagonal branch. Among the 18 single myocardial bridging 16 were in the course of anterior interventricular artery and two showed myocardial bridging in one of the diagonal branch of AIVA. There were 24 myocardial bridges in the course of AIVA, 16 as a part of single myocardial bridged hearts and 8 as a part of double myocardial bridged heart with the percentage of distribution were $2(8.33 \%)$ in the proximal $1 / 3^{\text {rd }}, 18(75 \%)$ were in middle $1 / 3^{\text {rd }}$ and $4(16.66 \%)$ were in distal $1 / 3^{\text {rd }}$. Conclusion: Due to the presence of high percentage of reported myocardial bridges in cadaveric hearts, the clinicians should always screen the young individuals and athletes having myocardial ischemia for the myocardial bridges along with other etiological factors.

Key words: Young individuals; Coronary artery; Sudden cardiac death; Anterior interventricular artery

\section{INTRODUCTION}

There are two coronary arteries which supplies the heart. These coronary arteries are epicardial in course and take origin from coronary sinuses. Myocardial bridging is a congenital variant of a coronary artery in which a portion of an epicardial coronary artery covered by the myocardium for varying lengths and depth, are termed as tunneled or mural coronary artery and the overlying myocardium as myocardial bridge. ${ }^{1}$ Recently in various studies it has been seen that it is one of the probable cause of sudden cardiac death in young athletes. ${ }^{2,3}$

Myocardial bridging was, first recognized anatomically by Reyman in $1732 .{ }^{4}$ It was first described as myocardial bridges by Geiringer in $1951^{5}$ and described angiographically by Portmann and Iwig in $1960 .{ }^{6}$ Ferreira et al. ${ }^{7}$ described two variants of myocardial bridging, superficial and deep. 
According to them in the Superficial variant coronary artery lies in the interventricular groove and crossed by muscles bundle at various angulation which may run perpendicular or at acute angle of it and the deep variant situated deep on the interventricular septum and was crossed by the longitudinal muscles bundle that comes from the apex of the heart which may be transverse, oblique and helical. Myocardial bridging is usually present in the middle region of anterior interventricular artery. ${ }^{8-10}$ The differences in the reported cases of myocardial bridging depends upon the techniques used for diagnosis. The incidence of myocardial bridging ranges from 5.4 to $85.7 \%$ by autopsy studies ${ }^{11-13}$ and from 0.5 to $10 \%$ by coronary angiography. ${ }^{14}$ Various studies have compared the different modalities and concluded that CCTA (coronary computed tomography angiography) is the best technique to diagnose myocardial bridging with the rate similar to that of the autopsy studies. The study of Tsujita et al. ${ }^{15}$ reported a significant difference in the detection rate of myocardial bridging in the individuals of anterior interventricular artery lesion by angiography and IVUS (intravascular ultrasound) was 3\% and 23\% respectively.

This difference is because in angiographic studies myocardial bridging is detected by the systolic compression of the tunneled segment. Detection rate can be improved by giving nitroglycerin or $\beta$-agonist. It is considered that during the cardiac cycle systolic compression of the tunneled coronary artery is infrequent in superficial variants while in case of deep variant, the overlying bridging fibers lead to the twisting of the tunneled segment resulting in hemodynamic compromise of coronary flow. During post mortem examination myocardial bridging is a common finding. It was thought to be a benign anatomic condition, but the following complications have been reported: ischemia and acute coronary syndromes, coronary spasm, ventricular septal rupture, arrhythmias (including supraventricular tachycardia and ventricular tachycardia), exercise-induced atrioventricular conduction block, early death after cardiac transplantation, and sudden death. In some studies it had been found that myocardial bridging was more in the population of hypertrophic cardiomyopathy patients and heart transplant patients, compared to the general population. ${ }^{16}$ The various autopsy series have been performed, with rates reported from 5\%-86\%. More recent studies involving CCTA find bridged coronary segments at rates similar to the autopsy series. ${ }^{17}$ The objectives of the present study was to know the myocardial bridge in the course of coronary arteries and know its prevalence by doing cadaveric dissection.

\section{MATERIALS AND METHODS}

Study was conducted in the department of Anatomy IMS, BHU, Varanasi. After cadaveric dissection of thoracic region by the MBBS students hearts were removed from the thoracic cavity by cutting the great vessels and were washed with tap water to remove the clot and were kept in glass jar containing $10 \%$ of formalin. We took already stored hearts of last 7 years of duration for the study and excluded the hearts having any gross pathology and traumatic damage. Forty nine hearts which were kept in the glass jar were dissected meticulously by using hand lens with fine and blunt forceps to see the distribution and location of myocardial bridging in the course of any of the coronary arteries. The right and left coronary arteries and its branches were dissected after careful removal of the epicardial fat. The point of origin of anterior interventricular artery (AIVA) from left coronary artery was noted and traced it till it termination on the apex of the heart. It was further divided into three equal segments and noted the location of myocardial bridge.The photographs were taken and the data were reported and analyzed.

\section{RESULT}

In the present study out of 49 dissected hearts, $26(53.06 \%)$ hearts had myocardial bridging (Table 1). In 26 myocardial bridged hearts total numbers of bridges noted to be 34 in number i.e 18 hearts (69.23\%) were having single myocardial bridging and 8 hearts $(30.76 \%)$ were having double myocardial bridging. Out of 18 single myocardial bridged hearts 16 hearts had myocardial bridge in the course of anterior interventricular artery (Figure 1) and 2 hearts had myocardial bridges in one of the diagonal branch of anterior interventricular artery (Figure 2). Out

\begin{tabular}{|c|c|}
\hline Coronary arteries with MB & $\begin{array}{l}\text { No. of cases out of } \\
26 \text { MB hearts }\end{array}$ \\
\hline Only in Anterior interventricular artery & $16(61.53 \%)$ \\
\hline $\begin{array}{l}\text { Only in diagonal branch of anterior } \\
\text { ventricular artery }\end{array}$ & $2(7.69 \%)$ \\
\hline $\begin{array}{l}\text { Both Anterior interventricular artery and } \\
\text { its Diagonal branch }\end{array}$ & $3(11.53 \%)$ \\
\hline $\begin{array}{l}\text { Both Posterior interventricularartey and } \\
\text { anterior interventricular artery }\end{array}$ & $5(19.23 \%)$ \\
\hline
\end{tabular}

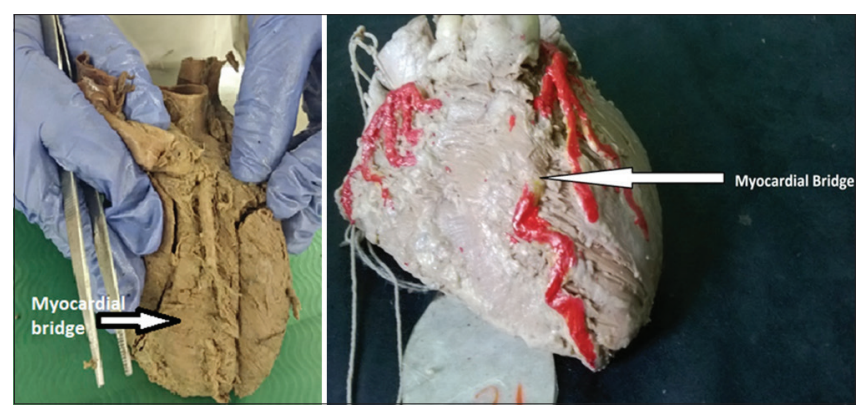

Figure 1: Arrow shows myocardial bridges in the course of anterior interventricular artery 
of 8 double bridged hearts 5 hearts (19.23\%) showed two bridges that were located in the course of anterior interventricular artery and posterior interventricular artery (Figure 3). Another 3 hearts (11.53\%) showed two bridges located on the course of anterior interventricular and its diagonal branch. Among the total number of 34 myocardial bridges found in 26 hearts $24(70.58 \%)$ were in the course of anterior interventricular artery, $5(14.70 \%)$ in PIVA and rest $5(14.70 \%)$ in one the diagonal branch of AIVA. 24 bridges present on the course of anterior interventricular artery showed the maximum percentage of distribution in middle $1 / 3^{\text {rd }}$ with 18 cases $(75 \%)$ followed by distal $1 / 3^{\text {rd }}$ with 4 cases $(16.66 \%)$ followed by proximal $1 / 3^{\text {rd }}$ with 2 cases $(8.33 \%)$ (Figure 4).

\section{DISCUSSION}

The usual course of coronary arteries are subepicardial and at its termination it enter into the myocardium but in case of myocardial bridging the different coronary arteries before its termination gets covered by the myocardium for varying length and depth and distally again reappear. Initially myocardial bridges was considered as a benign condition but due to increased sudden cardiac death in athletes who have been found to have a myocardial bridge as the only finding in postmortem examination made it a clinically important finding. The mechanism which causes clinically significant myocardial bridges are unknown but the most common proposed one are systolic compression of tunneled artery with sustained early diastolic diameter reduction. The diagnosis of Myocardial bridging becomes clinically important in patients who have angina and do not have the other risk factors and the evidence of ischemia. ${ }^{18,19}$ The embryology of myocardial bridges are that it is a secondary structures formed by the migration of myocytes over the subepicardial coronary arteries. On the basis of presence and absence of myocardial bridges three types of coronary artery are present. In rodents, goats and sheep coronary arteries are intramyocardial. In carnivores and human beings the coronary arteries are predominantly subepicardial in course. In horses and pigs coronary arteries are always subepicardial in course.

Initially only angiographic imaging was available but now newer diagnostic techniques such as coronary computed tomographic angiography (CCTA), intravascular ultrasound (IVUS), intracoronary doppler, and fractional flow reserve (FFR) are available. Various studies have been done for the treatment and they have found that the first line treatment is always $\beta$ blocker and calcium channel blocker and surgical myotomy needs to be performed in the refractory cases. Percutaneous coronary intervention in the form of stenting

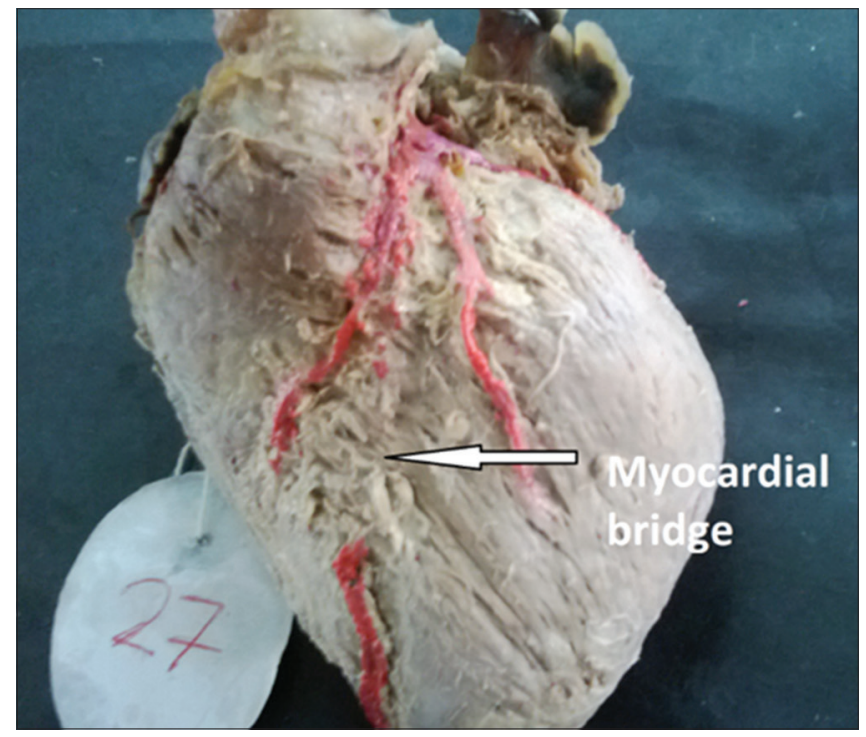

Figure 2: Shows myocardial bridge in the course of one of the diagonal branch of anterior interventricular artery (single bridge)
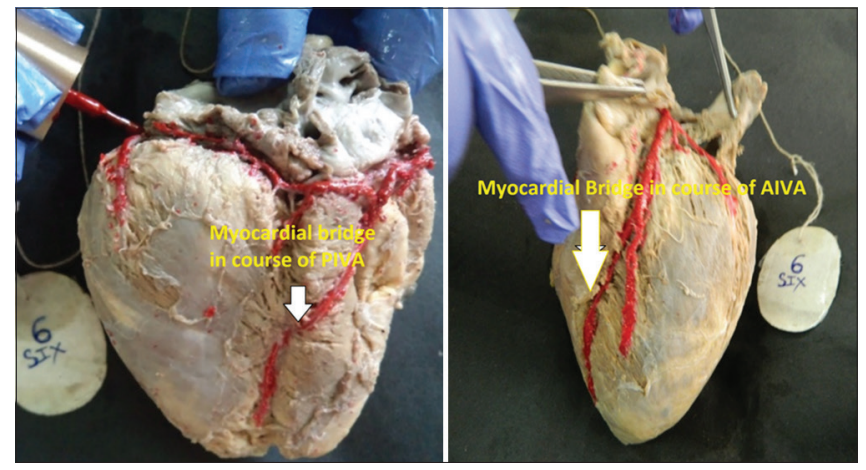

Figure 3: Shows myocardial bridge in the course of posterior interventricular artery on diaphragmatic surface as well as anterior interventricular artery on sternocostal surface in same heart

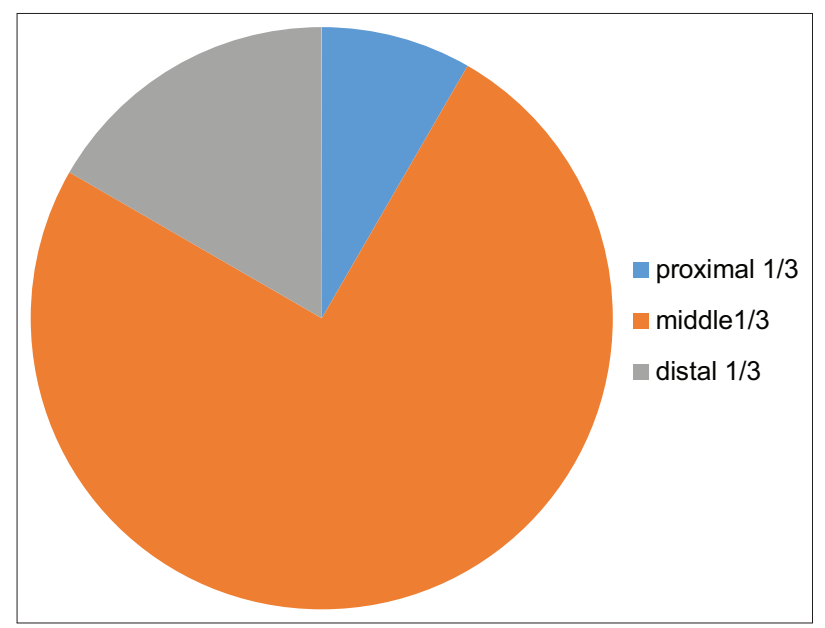

Figure 4: Pie diagram shows distribution of myocardial bridges in the course of anterior interventricular artery.

has been also used. Serious complication like stent fracture and coronary arteries perforation has been reported. 


\begin{tabular}{lcc}
$\begin{array}{l}\text { Table 2: Comparison of myocardial bridging with } \\
\text { other previous study }\end{array}$ & $\begin{array}{c}\text { \% of } \\
\text { myocardial } \\
\text { bridging }\end{array}$ & $\begin{array}{c}\% \text { of myocardial } \\
\text { bridging in the } \\
\text { course of AlVA }\end{array}$ \\
\hline Various study & $56 \%$ & - \\
\hline Ferreira(1991) & $54 \%$ & $35 \%$ \\
Baptista(1992) & $05 \%$ & $87 \%$ \\
Edwards(1956) $)^{13}$ & $86 \%$ & $60 \%$ \\
Polacek(1961) & $53.33 \%$ & $62.5 \%$ \\
Lujinović A, et al $(2013)^{21}$ & $36.7 \%$ & $36 \%$ \\
Srivastava Monica MS (2014) $)^{22}$ & $53.06 \%$ & $70.58 \%$ \\
Present study & \multicolumn{2}{l}{} \\
\hline
\end{tabular}

Nishikii et $\mathrm{al}^{20}$ has reported that exercise in myocardial bridge patients results in ventricular arrhythmias (premature ventricular contractions, exercise-induced non-sustained ventricular tachycardia) and abnormalities in repolarization (increased QTd).

Edwards ${ }^{13}$ reported myocardial bridging in 5\% cases and Polacek et a ${ }^{12}$ reported it in $86 \%$ cases. In the present study the myocardial bridging is $53.06 \%$ which is comparable to Lujinovi A et $\mathrm{al}^{21}$ and Ferreira et al. who observed it to be $53.33 \%$ and $55.6 \%$ respectively. In the observation of myocardial bridged hearts Edwards $(1956)^{13}$ Lujinović A et al. $(2013)^{21}$ reported maximum percentage of myocardial bridging in the course of anterior interventricular artery which is same of the present study. Polack $(1961)^{12}$ observed 167 number of bridges in 60 myocardial bridged hearts with maximum frequency of $60 \%$ was in the course of anterior interventricular artery. He also suggested that muscular bands are present since birth and their development is closely associated with the growth of adjacent artery (Table 2).

The myocardial bridging causes technical problem during coronary bypass surgery. During the bypass surgery of coronary arteries which is deeply situated beneath the bridge, may lead to the perforation of right ventricular wall.

When the location of myocardial bridges in course of Anterior interventricular artery were analysed, the most common sides were middle $1 / 3^{\text {rd }} 18(75 \%)$ followed by proximal $1 / 3^{\text {rd }} 2(8.33 \%)$ followed by distal $1 / 3^{\text {rd }} 4(16.66 \%)$. Other studies also found the maximum percentage in middle one third region.

The large variation in percentage of myocardial bridging are reported in various anatomical studies. The variation in percentage of myocardial bridging by dissection method by the different authors may be because of the observational and interpretational differences. Another cause of variation in percentage can be due to difference in ethnicity and demographic conditions.
The clinical significance of myocardial bridging is unclear, either it remain silent without causing any symptoms or it may be a contributing factor to the ischemia, infarction and sudden cardiac death. The number of studies published according to that the bridging protect against coronary atherosclerosis. It has been seen that bridged coronary segment does not having atherosclerosis and the segment proximal to the bridges are more prone for atherosclerosis.

\section{CONCLUSION}

Currently myocardial bridges are an attractive and fascinating area of research. The clinician should keep in mind about myocardial bridges especially when dealing with young individuals having ischemia in absence of any other cardiac risk factors. The surgeon while performing coronary bypass surgery especially in young patients should be aware that there can be presence of myocardial bridge which can result in complications during stenting.

\section{ACKNOWLEDGEMENT}

Nonteaching staff of dissection hall of Institute of Medical Sciences, Banaras Hindu University, Varanasi, Uttar Pradesh, India.

\section{REFERENCES}

1. Angelni P, Velasco JA and Flamm S. Coronary anomalies: incidence, pathophysiology, and clinical relevance. Circulation. 2002; 105:2449-2454.

https://doi.org/10.1161/01.CIR.0000016175.49835.57

2. Quaranta F, Guerra E, Sperandii F, De Santis F, Pigozzi F, Calò $\mathrm{L}$, et al. Myocarditis in athlete and myocardial bridge: An innocent bystander?. World journal of cardiology. 2015; 7(5), 293-298. https://doi.org/10.4330/wjc.v7.i5.293

3. Maron BJ, Shirani J, Poliac LC, Mathenge R, Roberts WC and Mueller FO. Sudden Death in Young Competitive Athletes: Clinical, Demographic, and Pathological Profiles. JAMA. 1996; 276(3):199-204.

https://doi.org/10.1001/jama.1996.03540030033028

4. Reyman HC. Disertatio de vasiscordispropriis. Bibl Anat. 1737; 2:359-379.

5. Geiringer E. The mural coronary. Am Heart J. 1951; 41(3):359-368. https://doi.org/10.1016/0002-8703(51)90036-1

6. Portmann WCand Iwig J.Dieintramuralekoronarieimangiogramm. FortschrRontgenstr 1960; 92:129-132.

https://doi.org/10.1055/s-0029-1226492

7. Ferreira AG Jr, Trotter SE, Konig B Jr, Decourt LV, Fox K and Olsen EG. Myocardial bridges: morphological and functional aspects. Br Heart J. 1991; 66:364-367. https://doi.org/10.1136/hrt.66.5.364

8. Faruqui AM, Maloy WC, Felner JM, Schlant RC, Logan WD and Symbas P. Symptomatic myocardial bridging of coronary artery. Am J Cardiol. 1978; 41:1305-1310. 
https://doi.org/10.1016/0002-9149(78)90890-1

9. Channer KS, Bukis E, Hartnell G and Rees JR. Myocardial bridging of the coronary arteries. Clin Radiol. 1989; 40:355-359. https://doi.org/10.1016/S0009-9260(89)80118-7

10. Irvin RG. The angiographic prevalence of myocardial bridging in man. Chest. 1982; 81:198-202.

https://doi.org/10.1378/chest.81.2.198

11. Baptista CA and DiDio LJ. The relationship between the directions of myocardial bridges and of the branches of the coronary arteries in the human heart. Surg Radiol Anat. 1992; 14(2):13740.

https://doi.org/10.1007/BF01794890

12. Polacek $P$ and Kralove $H$. Relation of myocardial bridges and loops on the coronary arteries to coronary occlusion. Am Heart $\mathrm{J}$ 1961; 61(1):44-52.

https://doi.org/10.1016/0002-8703(61)90515-4

13. Edwards JC, Burnsides C, Swarm Rl and LansingAl.Arteriosclerosis in the intramural and extramural portions of coronary arteries in the human heart. Circulation 1956;13(2):235-41. https://doi.org/10.1161/01.CIR.13.2.235

14. Ishimori T, Raizner AE, Chahine RA, Awdeh M and Luchi RJ. Myocardial bridges in man: clinical correlations and angiographic accentuation with nitroglycerin. Cathet Cardiovasc Diagn. 1977; 3:59-65.

https://doi.org/10.1002/ccd.1810030107

15. Tsujita K, Maehara A, Mintz GS, Stone GW, Moses JW and Leon MB.Comparison of angiographic and intravascular ultrasonic detection of myocardial bridging of the left anterior descending coronary artery. Am J Cardiol. 2008; 102:1608-1613. https://doi.org/10.1016/j.amjcard.2008.07.054

16. Wymore P, Yedlicka JW, Garcia-Medina V, Olivari MT,
Hunter DW, Castaneda- Zuniga WR, et al. The incidence of myocardial bridges in heart transplants. Cardiovasc Intervent Radiol. 1989; 12:202-206.

https://doi.org/10.1007/BF02577154

17. Konen E, Goitein O, Sternik L, Eshet $\mathrm{Y}$, Shemesh J and Di Segni E. The prevalence and anatomical patterns of intramuscular coronary arteries: a coronary computed tomography angiographic study. J Am Coll Cardiol. 2007; 49:587-593.

https://doi.org/10.1016/j.jacc.2006.09.039

18. Kulan K, Kulan C, Tuncer C, Komsuoglu B and Telatar M. Myocardial perfusion scintigraphy in a myocardial bridging of coronary artery. Clin Nucl Med. 1996; 21:888-889. https://doi.org/10.1097/00003072-199611000-00019

19. Lee YS, Moon DH, Shin JW, Park SW, Park SJ and Lee HK. Dipyridamole TI-201 SPECT imaging in patients with myocardial bridging. Clin Nucl Med. 1999; 24:759-764. https://doi.org/10.1097/00003072-199910000-00006

20. Nishikii-Tachibana M, Pargaonkar VS, Schnittger I, Haddad F, Rogers IS and Tremmel JA. Myocardial bridging is associated with exercise-induced ventricular arrhythmia and increases in QT dispersion. Ann Noninvasive Electrocardiol. 2018;23(2):e12492. https://doi.org/10.1111/anec.12492

21. Lujinović A, Kulenović A, Kapur E and Gojak R. Morphological aspects of myocardial bridges. Bosn J Basic Med Sci. 2013; 13(4):212-217. https://doi.org/10.17305/bjbms.2013.2304

22. Srivastava $M$, Dixit $A$, Sharma $V$, Yadav A, Srivastava DK. A study to find out the incidence of myocardial bridges in the formalin fixed hearts and its correlates. IOSR Journal of Dental and Medical Sciences. 2014; 13(11):66-69. https://doi.org/10.9790/0853-131156669

\section{Author's contribution:}

GR- Dissection of Coronary arteries in cadaveric hearts and analysis of myocardial bridging in coronary arteries and review of literature; SK- Dissection of coronary arteries and analysis of myocardial bridging manuscript writing; RS- Concept and Supervision of overall study.

Work attributed to:

Department of Anatomy, Institute of Medical Sciences, Banaras Hindu University, Varanasi, Uttar Pradesh, India.

\section{Orcid ID:}

Dr Gunjan Rai- (D) https://orcid.org/0000-0002-5285-7861

Dr Soumya Khanna- (D) https://orcid.org/0000-0001-6121-9282

Dr Royana Singh-1 https://orcid.org/0000-0002-8509-0652

Source of Funding: None, Conflict of Interest: None. 